\title{
A COMPARATIVE STUDY OF POSTOPERATIVE COMPLICATIONS IN EMERGENCY VERSUS ELECTIVE LAPAROTOMY
}

\section{Surgery}

\section{Dr. Binit Prasad}

M.B.B.S., M.S. (Gen. Surgery),Senior Resident, Department of Surgery, Indira Gandhi Institute of Medical Sciences (IGIMS), Patna, Bihar.

\begin{tabular}{ll}
\hline $\begin{array}{l}\text { Dr. Mukesh } \\
\text { Kumar* }\end{array}$ & $\begin{array}{l}\text { Associate Professor, Department of Surgery, Indira Gandhi Institute of Medical Sciences } \\
\text { (IGIMS), Patna, Bihar. *Corresponding Author }\end{array}$ \\
\hline
\end{tabular}

\section{Dr. Debarshi Jana}

Young Scientist (DST) Institute of Post-Graduate Medical Education and Research, A.J.C. Bose Road, Kolkata-700020, West Bengal, India.

\section{ABSTRACT}

Background: The incidences of post-operative complications are higher after laparotomy particularly in emergency.This study was aimed to evaluate and compare postoperative complications after emergency versus elective laparotomy performed at IGIMS, Patna.

Methods: This comparative study was carried out at Department of General Surgery in Indira Gandhi Institute of Medical Sciences, Patna, Bihar during period of January 2019 to December 2019 All the patients who underwent laparotomy (elective or emergency) were included in the study. Demographic data about patients was collected and noted in pro forma. Patients were followed in postoperative period and any complication developed recorded. Complications compared according to nature of laparotomy whether elective or emergency.

Results: A total of 350 patients underwent emergency laparotomy and 50 patients underwent elective laparotomy.128 (36.57\%) patients developed complications following emergency laparotomy while $11(22 \%)$ patients developed complication after elective laparotomy. Postoperative complications following emergency laparotomy included pyrexia (18.2\%) followed by nausea and vomiting (12\%), wound infection (11.4\%), respiratory tract infection $(6.85 \%)$, urinary tract infection $(2.28 \%)$, gastrointestinal complications $(3.71 \%)$, toxemia and septicaemia ( $8 \%)$. After elective laparotomy $20 \%$ patients showed postoperative fever, $10 \%$ patients suffered from postoperative nausea and vomiting and wound infection was noted in $4 \%$ patients.

Conclusions: In comparison to elective laparotomy postoperative complications are more common in emergencylaparotomy.

\section{KEYWORDS}

Complications, Emergency, Elective, Laparotomy, Postoperative

\section{INTRODUCTION}

Laparotomy is a most common surgical procedure done by routine surgical team. In surgical language, the word laparotomy explains exploration of the abdomen and proceed further according to the cause identified.

Postoperative complication may be defined as any negative outcome as perceived by the surgeon or by the patient. It may occur intraoperatively in the immediatepostoperative period, or later on. Complications following abdominal surgery role a formidable challenge to surgeon in a general surgery unit, where abdominal surgery constitutes bulk of major operations. They are the chief weakness of surgeon's craftsmanship on operation table. Commencing as a seemingly minor disturbance and if allowed to persist they can jeopardize the patient recovery and even result in a fatal outcome. Postoperative complication may occur after laparotomy whether elective or emergency.

Various factors like proper resuscitation, meticulous surgical technique, age, any co-morbid condition (coronary artery disease, diabetes mellitus, hypertension, any chronic illness), anaesthesia technique and postoperative care contribute to final result.

Adverse events that are closely related to processes of care, such as postoperative complications, may be a better measure of quality than death rates or other intermediate outcomes. Therefore, early detection and proper intervention can reduce the morbidity and mortality related with complication.

\section{MATERIALAND METHODS}

This study was conducted at Department of General Surgery in Indira Gandhi Institute of Medical Sciences (IGIMS), Patna, Bihar. Thetarget population was patients undergoing emergency/elective laparotomy admitted to the general surgical wards. This was a hospital based, single centre longitudinal prospective observational study from January 2019 to December 2019 including 350 patients who underwent emergency laparotomy and 50 patients who underwent elective laparotomy.

The data of patients who underwent elective or emergency laparotomy was noted on a pro forma. A detailed history and clinical examination was conducted. Basic investigations like random blood sugar, complete blood count, urinalysis, serum urea/creatinine, serum electrolytes, chest radiograph, electrocardiograph, hepatitis B and HIV profile and blood grouping and cross matching were done. Abdominal radiographs and ultrasonography was also done where required. Patients who presented with acute abdomen and needed immediate surgery, after resuscitation with IV fluids and supportive treatment, Foley's catheterization and nasogastric intubation, underwent emergency laparotomy.

In elective group patients, beside pre-operative evaluation as done in case of emergency laparotomy, correction of any co-morbid condition like anaemia, diabetes, hypertension, respiratory infection was done before laparotomy.

Pre-anaesthetic assessment was made and written/ informed consen was taken after counseling regarding the condition of the patient and the possible outcomes. Under general/spinal anaesthesia the operative field was prepared with povidone iodine and all the patients were opened through a midline abdominal incision. After surgery patients were observed for any postoperative complication and mortality with predisposing factors. Persistent postoperative fever ( $>48$ hours), postoperative nausea and vomiting and respiratory tract infections were monitored regularly.

Patients were evaluated for both local and systemic complication. Examination of the wound related complication was started from the second postoperative day and patients having postoperative pyrexia and serosanguinous/serous/pus discharge coming from main wound site were included in this complication. They were further followed up for sequelae like wound gapping and burst abdomen.

Patients were also evaluated for post-operative systemic complications like pulmonary, gastrointestinal and urinary complications.

On the basis of clinical examination and investigations (blood examination and $\mathrm{X}$ ray chest) respiratory tract infection was identified. Gastrointestinal complications observed during postoperative period included postoperative ileus, intestinal obstruction, diarrhea, and gastrointestinal fistula (faecal, bilious fluid discharge from main wound or drain site). Septicemia was also noted in post-operative period and mortality associated with it was also recorded. 
RESULTS

Total 400 patients underwent laparotomy, among which 350 patients underwent emergency laparotomy and 50 patients underwent elective laparotomy. $270(77.14 \%)$ patients were male and $80(14.28 \%)$ were female. The age ranged between 8-70 years. The majority of cases were of acute abdomen/peritonitis. Peptic perforation peritonitis constituted $110(31.42 \%)$ cases followed by typhoid perforation peritonitis $85(24.28 \%)$, intestinal obstruction $76(21.7 \%)$, blunt and penetrating trauma abdomen $28(7.98 \%)$, appendicular perforation 17 $(4.85 \%)$ and other surgeries were performed as mentioned in table below (Table 1). 128 (36.57\%) patients developed complications after emergency laparotomy in postoperative period.

Most common complication evident was postoperative pyrexia in 70 $(20 \%)$ patients followed by wound related complication in 43 $(12.28 \%)$ patients and postoperative nausea and vomiting in $42(12 \%)$ patients, respiratory complications seen in $24(6.85 \%)$ patients, fecal fistula observed in $7(2 \%)$ patients, post-operative obstruction seen in 6 $(1.71 \%)$ patients, toxemia and septicemia developed in $28(8 \%)$ cases. Deep vein thrombosis was seen in 1 patient. 30 patients died in postoperative period because of complications (majority because of septicemia) (Table 2).

Table 1: Distribution of cases underwent emergency laparotomy according to diagnosis

\begin{tabular}{|l|l|l|l|}
\hline Diagnosis & & $\begin{array}{l}\text { Total No. } \\
\text { of cases }\end{array}$ & $\begin{array}{l}\text { Percentage } \\
(\mathbf{\%})\end{array}$ \\
\hline $\begin{array}{l}\text { Peptic perforation } \\
\text { peritonitis }\end{array}$ & 110 & 31.42 \\
\hline $\begin{array}{l}\text { Typhoid } \\
\text { perforation } \\
\text { peritonitis }\end{array}$ & & 85 & 24.28 \\
\hline $\begin{array}{l}\text { Intestinal } \\
\text { obstruction }\end{array}$ & Small bowel & 45 & 12.85 \\
\cline { 2 - 4 } Trauma & Harge bowel & 31 & 8.85 \\
\cline { 2 - 4 } & $\begin{array}{l}\text { Jejunal perforation } \\
\text { peritonitis }\end{array}$ & 12 & 3.42 \\
\cline { 2 - 4 } & Colonic perforation & 6 & 2.85 \\
\hline Pyoperitonium & & 21 & 6 \\
\hline $\begin{array}{l}\text { Abdominal } \\
\text { tuberculosis }\end{array}$ & & 13 & 3.71 \\
\hline $\begin{array}{l}\text { Appendicular } \\
\text { perforation }\end{array}$ & & 17 & 4.85 \\
\hline
\end{tabular}

Table 2: Distribution of complications after emergency laparotomy

\begin{tabular}{|c|c|c|c|}
\hline Complications & & $\begin{array}{c}\text { No. of } \\
\text { cases }\end{array}$ & $\begin{array}{c}\text { Percentage } \\
\mathbf{( \% )}\end{array}$ \\
\hline Post-operative fever & & 70 & 20 \\
\hline $\begin{array}{c}\text { Postoperative nausea and } \\
\text { vomiting }\end{array}$ & & 42 & 12 \\
\hline \multirow{2}{*}{$\begin{array}{c}\text { Wound related } \\
\text { complication }\end{array}$} & Wound infection & 34 & 9.71 \\
\cline { 2 - 4 } & Minor gapping & 7 & 2 \\
\cline { 2 - 4 } & Burst abdomen & 2 & 0.57 \\
\hline \multirow{3}{*}{\begin{tabular}{c} 
Respiratory complications \\
\cline { 2 - 4 }
\end{tabular}} & Atelactasis & 15 & 4.28 \\
\cline { 2 - 4 } & Tracheobronchitis & 10 & 2.85 \\
\cline { 2 - 4 } & Pneumonia & 6 & 1.71 \\
\cline { 2 - 4 } & Pleural effusion or & 2 & 0.57 \\
\cline { 2 - 4 } & empyema & 1 & 0.28 \\
\hline Toxemia and septicemia & ARDS & 28 & 8 \\
\hline Faecal fistula & & 6 & 1.71 \\
\hline Post-operative obstruction & & & 2 \\
\hline
\end{tabular}

Table 3: Distribution of cases underwent elective laparotomy according to diagnosis.

\begin{tabular}{|c|c|c|c|}
\hline Diagnosis & & $\begin{array}{c}\text { No. of } \\
\text { cases }\end{array}$ & $\begin{array}{c}\text { Percentage } \\
(\mathbf{\%})\end{array}$ \\
\hline \multirow{3}{*}{ Ovarian Masses } & Benign ovarian cyst & 16 & 32 \\
\cline { 2 - 2 } & Tobo-ovarian mass & & \\
\cline { 2 - 3 } & Mucinous cystadenoma ovary & & 10 \\
\hline $\begin{array}{c}\text { Retroperitoneal } \\
\text { mass }\end{array}$ & 5 & 15 & 30 \\
\hline Mesentric cyst & & 15 & 10 \\
\hline
\end{tabular}

Abdominal tuberculosis

Colonic carcinoma

20

Most complication occurred in typhoid perforation peritonitis 37 (28.90\%), intestinal obstruction $35(27.34 \%)$ and peptic perforation peritonitis $34(26.56 \%)$ cases. Many patients were affected from more than one complication.

Out of 50 patients who underwent elective laparotomy $11(22 \%)$ patients were male and $39(78 \%)$ patients were female and age ranged from 10-56 years. The cases included ovarian masses $16(32 \%)$, retroperitoneal mass $5(10 \%)$, mesenteric cyst $15(30 \%)$, abdominal tuberculosis $10(20 \%)$ and colonic carcinoma $4(8 \%)$ as depicted in Table 3 .

Among 50 patients undergoing elective laparotomy complications was seen in $11(22 \%)$ patients. Most common complication was postoperative pyrexia seen in $10(20 \%)$ patients, followed by nausea and vomiting in $5(10 \%)$ cases, wound infection recorded in $3(6 \%)$ patients and pulmonary complication in $3(6 \%)$ cases.

No mortality recorded in 30 days follow up period. Frequency of postoperative complication following emergency versus elective laparotomy.

\section{DISCUSSION}

The emergency laparotomy for acute abdomen is a major test of the surgical skills of a surgeon. Postoperative care is as essential as the preoperative preparation for a successful outcome. Deficient care in either may produce unsatisfactory results irrespective of the standard of surgery. The aim of meticulous postoperative care is early detection and immediate treatment of postoperative complications.

In this study complications were recorded in 128 patients after emergency laparotomy as compared to 11 patients after elective laparotomy. In emergency laparotomy, most common complication found was post-operative fever seen in $20 \%$ followed by nausea and vomiting in $12 \%$ and wound infection in $12 \%$ as compared to elective laparotomy where $20 \%$ patients showed postoperative fever followed by nausea and vomiting in $10 \%$ and wound infection in $6 \%$ patients. A study done by Jawaid et al, also recorded postoperative fever in $18.2 \%$ as the commonest complication, postoperative nausea and vomiting in $11.6 \%$ cases and wound infection in $11.4 \%$ cases after emergency laparotomy.

Different studies show that fever is common among postoperative patients. In this study also fever is the most common complication after emergency as well as elective laparotomy. After emergency laparotomy as well as elective laparotomy fever was seen in $20 \%$ of cases. Most early postoperative fever (temperature above $38^{\circ} \mathrm{C}$ / $100.4^{\circ} \mathrm{F}$ ) for 48 hours or more is caused by the inflammatory stimulus of surgery and resolves spontaneously. However, postoperative fevers can also be a manifestation of a serious complication. Pyrexia within 48 hours of surgery is often due to pulmonary atelectasis. Between 48 hours and five days, pyrexia may be the result of thrombophlebitis or infection of the urinary tract or the chest, and, more than five days after surgery, a wound infection or anastomotic breakdown should be suspected. Between 7 to 10 days deep venous thrombosis and pulmonary embolus were the common causes. A study in critically ill surgical patients showed that $26 \%$ of patients developed postoperative fever. A low percentage of fever in elective laparotomy may be because of less chances of wound infection, chest infection and less critically ill patients in this group.

Postoperative nausea and vomiting (PONV) are among the most common adverse events after surgery and anaesthesia. The overall incidence of PONV is about 30 percent but can be as high as 70 percent in high risk patients. Most episodes of postoperative nausea and vomiting resolve within 24 hours. In present study PONV documented in $12 \%$ cases after emergency laparotomy and $10 \%$ after elective laparotomy.

Wound infection is a well-recognized complication of surgical treatment and sometimes places a high burden on hospital resources. It is the most common nosocomial infection, accounting for $38 \%$ of all such infections. In present study wound infection occurred in $12.28 \%$ after emergency and 6\% after elective laparotomy. A study from Saudi Arabia recorded an overall infection rate of $9 \%$ while another study from the same country showed infection rate of $1.38 \%$. Low rate of 
wound related complications in elective laparotomy may be because of less contamination of peritoneal cavity and wound site at the time of surgery and better nutritional status of patient undergoing elective laparotomy.

La De Sa found overall 38.28\% wound infection rate in clean contaminated cases compared with $10.48 \%$ infection rate in clean cases. Garia Baldi et al and PL Nandi also pointed out bacterial contamination of wound at the time of operation being most important factors. Foothill hospital study demonstrated that clean cases were associated with $1.5 \%$ wound infection rate while clean contaminated; $7.7 \%$, contaminated; $15.2 \%$, highly contaminated cases were associated with $40.0 \%$ wound infection rate. $12.28 \%$ wound infection after emergency laparotomy and $6 \%$ after elective laparotomy is consistent with foothill hospital study.

Incidence of burst abdomen following abdominal surgery has been variably reported by authors like Wolff; $2.6 \%$, Efron; $2.3 \%$, Lehman at al; $2.5 \%$, Parmar G; $5 \%$. Incidence of burst abdomen following emergency laparotomy was $0.57 \%$, while no case of burst abdomen found after elective laparotomy in present study.

Postoperative pulmonary complications account for a substantial proportion of morbidity and mortality related to surgery and anesthesia and lead to longer hospital stays. The incidence of post-operative pulmonary complication varies from 5 to $60 \%$ as reported by L.G.G. Serejo et al and Deodhar. In present series $9.7 \%$ patients developed pulmonary complications following emergency laparotomy while $6 \%$ patients suffered from pulmonary complication after elective laparotomy. The low incidence of pulmonary complications in present series is due to better screening of patients, effective pre-operative control of respiratory tract infection, and postoperative physiotherapy.

Among gastrointestinal complications, 7 (2\%) cases of faecal fistula and $6(1.71 \%)$ cases of postoperative obstruction observed after emergency laparotomy while no gastrointestinal complication seen following elective laparotomy. Edmunds reported $1.4 \%$ incidence of fistula in his study.

Septicemia, a grave complication, was seen in 28 patients undergone emergency laparotomy while no case of septicemia recorded after elective laparotomy. 30 cases died in postoperative period after emergency laparotomy and no mortality recorded after elective laparotomy. Septicemia found to be most attributable factor for mortality in postoperative period following emergency laparotomy.

Venous thromboembolism (VTE) is considered to be a significant cause of morbidity and mortality in hospitalized patients, especially in those undergoing major surgical procedure. In present study only one case of DVT was documented after emergency laparotomy for typhoid perforation peritonitis. In the absence of prophylaxis, VTE rates as high as $25 \%$ have been reported following general surgery. In the United States and Europe, DVT is present in over 5 million events each year, while PE is present in over 500,000 cases. It has been perceived to be a rare disorder in Asians.

\section{CONCLUSION}

Postoperative complications increase patient morbidity and mortality and are a target for quality improvement programs. Many complications may be prevented by thorough preoperative evaluation, sound surgical technique and careful follow-up care. When we studied possible complications following elective surgery and those following urgent/emergency surgery, a debatable issue was the possibility of significant differences between them. The emergency laparotomies are also more common than elective laparotomies especially at peripheral centres.

In present study, the complication rate after emergency laparotomies is higher as compared to the elective laparotomies. The commonest problems being postoperative fever, wound infection and postoperative nausea and vomiting.

Despite the limitations of the current literature, this study can be useful for clinicians, individuals, and families making the difficult decision to undergo an emergency or elective abdominal surgery. Future studies should consider the effect of complications on those outcomes that are most important to the individual patient.

\section{REFERENCES}

1. Al HashemyAM, Seleem MI, Khan ZA, Nowry SM. Postoperative wound infection in surgical procedures. Saudi Med J. 2004;25(8):11223.

2. Alicia JM, Teresa CH, Michele LP, Leah CS, William RJ. Guideline for prevention of surgical site infection. Infect Control Hosp Epidemiol. 1999;20(4):24778

3. Barie PS, Hydo LJ, Eachempati SR. Causes and consequences of fever complicating critical surgical illness. Surg Infect. 2004;5(2):14559.

4. Davidson B, Rai R. Postoperative care of surgical patients. Student BMJ. 1999;7:99101. Desa LA, Sathe MJ, Bapat RD. Factors influencing wound infection (a prospective study of 280 cases). Postgrad Med. 1984;30(4):232.18.

6. Driscoll P, Farmery AD, Bulstrode CJK. Post-operative care. In: Russel RCG, Williams NS, Bulstrode CJK. Bailey and Love's short practice of surgery. 24th edn. New York: Oxford University Press; 2004:1436-49.

7. Galicier C, Richet H. A prospective study of postoperative fever in a general surgery department. Infect Control. 1985;6(12):48790.

8. Gan TJ. Postoperative nausea and vomiting can it be eliminated? JAMA. 2002;287:12336.

9. Garibaldi RA, Brodine S, Matsumiya S, Coleman Evidence for the noninfectious etiology of early postoperative fever. Infect Control. 1985;6(7):2737.

10. Guinn S, Castro FP Jr, Garcia R, Barrack RL. Fever following total knee arthroplasty. Guinn S, Castro FP Jr, Garcia R, B

11. Hobar PC, Masson JA, Herrera R, Ginsburg CM, Sklar F, Sinn DP, et al. Fever after craniofacial surgery in the infant under 24 months of age. Plast Reconstr Surg. 1998;102(1):326.

12. Jawaid M, Masood Z, Iqbal SA. Post-operative complications in a general surgical ward of a teaching hospital. Pak J Med Sci. 2006;22:171-5.

13. Kazemi-Kjellberg F, Henzi I, Tramèr MR. Treatment of established postoperative nausea and vomiting: a quantitative systematic review. BMC Anesthesiol. 2001:1:2.

14. Makhtar AM, El Tahwy AT, Khalaf RM, Bahnassy Postoperative wound infection: aetiology, pre-disposing factors and recommendation for control. Saudi Med J. 1993; 14:3236.

15. Nandi PL, Rajan SS, Mak KC, Chan SC, So YP. Surgical wound infection. Hong Kong Med J. 1999.19.

16. Parmar G, Gohil A, Hathila VP. Burst abdomen- a grave postoperative complication. Internet J Surg. 2009;20(1).

17. Serejo LG, da Silva-Júnior FP, Bastos JP, de Bruin GS, Mota RM, de Bruin PF. Risk factors for pulmonarycomplicationsafteremergency abdominal surgery. Respiratory Med. 2007;101(4):808-13.

18. Smetana GW. Preoperative pulmonary evaluation. Engl J Med. 1999;340:937-44 